\title{
Improving evapotranspiration estimation in pasture and native vegetation models using flux tower data, remote sensing and global optimisation
}

\author{
$\underline{\text { J. Owens }}^{\text {a }}$, J. Carter ${ }^{\text {b }}$, G. Fraser ${ }^{\text {b }}$, J. Cleverly ${ }^{\text {c }}$, L. Hutley ${ }^{\text {d }}$ and J. Barnetson $^{\text {e }}$ \\ ${ }^{a}$ Centre for Agricultural Engineering, University of Southern Queensland, Toowoomba, Queensland \\ ${ }^{b}$ Grazing Land Systems Group, Department of Environment and Science, Brisbane, Queensland \\ ${ }^{c}$ Terrestrial Ecosystem Research Network, University of Technology Sydney, New South Wales \\ ${ }^{d}$ Research Institute for the Environment and Livelihoods, Charles Darwin University, NT \\ ${ }^{e}$ Centre for Applied Climate Sciences, University of Southern Queensland, Brisbane, Queensland \\ Email:jo.owens@usq.edu.au
}

\begin{abstract}
GRASP is a biophysical model of soil water balance, pasture growth and animal production developed for northern Australian grasses in wooded and non-wooded systems. The intention of this work is to improve predictions from the GRASP model of evapotranspiration, soil water balance and subsequent pasture biomass and cover in tree-grass systems. This work feeds into the operational modelling system of GRASP that is disseminated through the FORAGE and AussieGRASS online systems, available at the Long Paddock website (https://www.longpaddock.qld.gov.au/forage). The GRASP model operates at 3 different scales: Cedar GRASP (paddock scale), FORAGE (property scale) and AussieGRASS (continental scale for Australia). The Cedar version is used for model development and research on grazing trials in Queensland and the Northern Territory. FORAGE is an online system for Queensland that generates and distributes customised PDF reports with information for individual properties. Currently over 2000 reports are requested per month for use by extension providers (government and private), consultants (valuers, agents), researchers (universities and government) and land managers. AussieGRASS products are currently used within the Queensland government to assist with drought declaration assessments and a monthly Climate Outlook and Review delivered through https://www.usq.edu.au/research/environmental-sciences/qdmc-drought
\end{abstract}

This paper documents the parameterisation and improvements to GRASP for estimating evapotranspiration in tree-grass systems. GRASP was overestimating the daily rate of evapotranspiration, particularly in wooded systems during the first days after rainfall events, with evapotranspiration often exceeding 1.3 times pan evaporation (Allen et al., 1998). Model partitioning of evapotranspiration into soil evaporation, grass and tree transpiration also needed adjustment to prevent excessive water loss. Incorporating daily measurements of evapotranspiration from TERN flux tower data provides the capacity to evaluate and improve the estimation of evapotranspiration in GRASP. Model changes include incorporation of satellite-derived fractional ground cover index for green and total cover in the understorey and persistent green for foliage projected cover to further improve the modelling by constraining estimates of evapotranspiration components. Combining field data with remotely sensed data and a global optimiser in an automated system provides the ability to inform model parameterisation and evaluation. Improving evapotranspiration modelling improves the soil water balance, pasture growth, tree-grass competition and safe carrying capacity, where animal numbers are matched to available pasture. Implications for these model changes and evaluation are significant, as this improves our capacity to model grazing land management issues such as runoff, export of sediment to the reef and sustainable long-term carrying capacity.

Key learnings from the optimisation experiments revealed where the model needed improvements, along with careful consideration of trade-offs in regard to variable weighting when optimising multiple measured data groups (such as soil moisture, evapotranspiration and green cover). Model improvements removed the 'spikes' in daily evapotranspiration, compared well to measured data and reduced estimated tree transpiration. Daily estimates of surface soil moisture from remote sensing platforms can be used in model calibration but first require model processes and parameterisation to be appropriate at daily time steps. Calibration of evapotranspiration at a daily time step has not been tested before with GRASP due to the lack of high quality daily data sets, especially from mixed tree and grass systems. These results demonstrate the improvements in GRASP for estimating daily and monthly evapotranspiration in mixed tree and grass systems.

Keywords: Fractional cover, woody vegetation, parameter estimation, remote sensing, model optimisation 
Owens et al., Improving evapotranspiration estimation in pasture and native vegetation models using flux tower data, remote sensing and global optimisation

\section{INTRODUCTION}

Understanding the water balance is important for sustainable management of grasses, woody vegetation, land and water resources. This understanding is useful for assessing how changes in climate, land use or management can alter the hydrological behaviour of catchments such as partitioning of rainfall into soil evaporation, canopy evaporation, grass transpiration, tree transpiration, runoff and drainage. For cleared and open pastures, the development of GRASP has been well supported by field measurements of soil water content, pasture yield and cover. However, for woodlands, there have been very few measurements, and model development has concentrated on simulating the effects of tree-grass competition on pasture yield. As approximately 50\% of Queensland has some tree cover, improvements to estimates of tree transpiration and evapotranspiration will increase our confidence in modelling areas with woody vegetation.

The purpose of our study is to improve the modelling of the rate of evapotranspiration in the GRASP model, particularly where woody plants are an important component. A secondary aim is to evaluate and improve the partitioning of evapotranspiration into tree transpiration, grass transpiration, soil evaporation, rainfall interception and canopy evaporation. These parts of the model are difficult to test because of lack of measured data. The GRASP model has been extensively tested in northern Australia against measured soil water and pasture biomass data from over 100 experimental sites (Day et al., 1997). This is the first time we have evaluated GRASP against measured daily evapotranspiration data. These model improvements will be extended to users through Cedar GRASP and our operational tools FORAGE (for all land types in Queensland) and AussieGRASS (continental scale for Australia) delivered via the Long paddock website (https://www.longpaddock.qld.gov.au).

In our initial study, the GRASP model was used to estimate evapotranspiration and green cover for a site in central Australia where measured evapotranspiration data was available from an eddy covariance flux tower. We utilised satellite-derived fractional ground cover index for green cover and total cover in the understorey, as well as persistent green cover for foliage projected cover (FPC) to evaluate and improve modeling at this site. We also compared model estimation of runoff and evapotranspiration with the AWRA model (Frost et al. 2018), recharge against tracer estimates (Harrington et al. 2002), canopy interception in mulga (Pressland 1973) and tree water use data collected by O'Grady (2009). This paper describes the modelling and optimisation approach using remotely sensed ground cover and FPC data with measured flux tower evapotranspiration data and global optimisation tools to inform model parameterisation.

\section{STUDY AREA AND DATA}

\subsection{Description of the study area}

This study uses measured evapotranspiration data from a flux tower (Cleverly et al. 2013, Eamus et al. 2013) and satellite-derived fractional ground cover data for the Terrestrial Ecosystem Research Network's (TERN) Alice Mulga SuperSite on Pine Hill cattle station in the Ti Tree basin, located approximately 200 $\mathrm{km}$ north of Alice Springs $\left(22.28^{\circ} \mathrm{S}, 133.25^{\circ} \mathrm{E}\right.$, Figure 1). This ecosystem is a savanna woodland which consists of a discontinuous tree layer (tree basal area of $8 \mathrm{~m}^{2} \mathrm{ha}^{-1}$ and a stem density of approximately 3,300 stems ha $^{-}$ 1) over a grassy understorey. The dominant grasses form a nearly complete cover when soil moisture conditions permit. The soil is characterized as a Red Kandosol which is typical of large portions of semi-arid Australia. This site in particular was chosen from a range

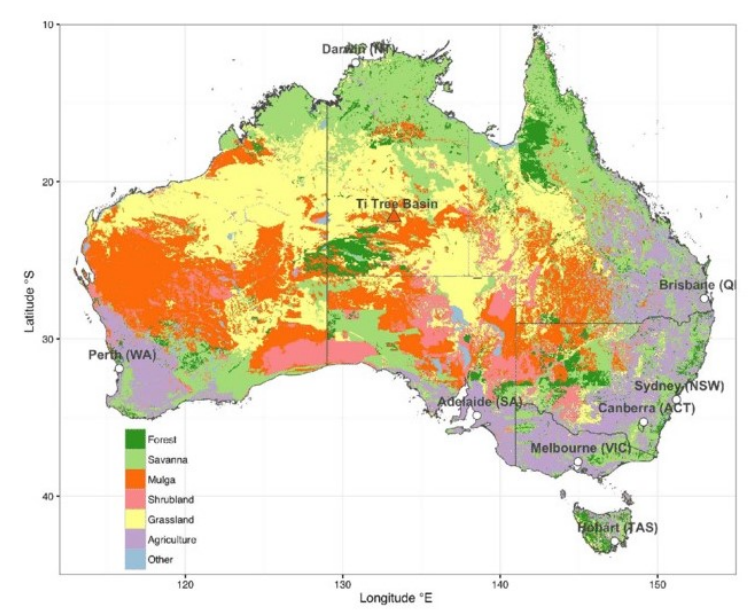

Figure 1. Distribution of major vegetation types in Australia where groups were reclassified from the original 26 National Vegetation Information System - Major Vegetation Groups. From Eamus et al. (2016), CC-BY. of northern Australian flux tower locations as it contained a mixture of trees and grasses, and it was very unlikely to have access to an aquifer (Cleverly et al. 2013), which would complicate estimation of evapotranspiration. The parameters from this study will help to describe mulga landscapes and land types in particular and other tree-grass systems in general. This is a key gap because mulga cover 20\%-25\% of the Australian continent (Figure 1; Eamus et al. 2016), and the area of the mulga bioregion within Queensland is also very large at $251,640 \mathrm{~km}^{2}$. 
Owens et al., Improving evapotranspiration estimation in pasture and native vegetation models using flux tower data, remote sensing and global optimisation

Daily interpolated climate data for the location were obtained from the SILO Data Drill (Jeffrey et al., 2001). Long-term average annual rainfall for the hydrological year (31 July to 1 August) is approximately $300 \mathrm{~mm}$, with pan evaporation being about ten times larger at 3,010 $\mathrm{mm}$. Rainfall and evapotranspiration data were extracted from the primary TERN OzFlux tower at the Alice Mulga SuperSite (FLUXNET code AU-ASM; Cleverly et al. 2013). Fluxes were measured at $11.7 \mathrm{~m}$ height above the $6.5 \mathrm{~m}$ canopy, were computed from the covariance between vertical windspeed and absolute humidity every 30 minutes and were gapfilled using a self-organising linear output (SOLO) type of artificial neural network (Eamus et al. 2013). We aggregated the data from October 2010 to December 2018 to report daily values at 9am for matching to SILO climate data.

Field measurements of ground cover were made in the flux tower footprint on 21/05/2014 by TERN AusPlots (https://www.tern.org.au/AusPlots). These field measurements indicated a FPC of $24 \%$ for the woody component and provided a check on remotely sensed estimates of cover components. Satellite data for deriving cover was extracted from the United States Geological Survey's Landsat dataset for modelling long-term trends, and the European Space Agency's Copernicus program of Sentinel satellites. All single date, cloud free, Landsat based estimates of fractional ground cover were used to track the dynamics of ground cover over the study period, and persistent green cover was extracted to follow dynamics of the tree canopies. These data were extracted from daily Landsat fractional/ground cover imagery from 2010 to 2018 from the QLD Government Remote Sensing Centre data store on (29/1/2019) and averaged over an area of approximately seven hectares centered at the flux tower. The satellite-derived data used for modelling were fractional green cover, total cover (green and dry) and persistent green (an index of tree FPC). We also extracted FPC data from Sentinel-2 to compare tree density between the flux tower site and historical sapflow measurement sites.

\section{METHODOLOGY}

\subsection{The GRASP model and modelling approach}

GRASP is a biophysical model of soil water balance, pasture growth and animal production developed for northern Australian grasses in wooded and non-wooded systems (Rickert et al. 2000). The soil water balance is calculated on a daily basis as the difference between inputs (rainfall) and outputs (runoff, drainage, canopy evaporation, soil evaporation and transpiration by grass and trees) in four soil layers of variable thickness and water holding characteristics. Pasture and tree transpiration and soil evaporation are calculated separately from potential rates that are adjusted based on soil water availability. The following options were used in the GRASP model (Cedar version 1.2) to improve modelling of tree transpiration: (a) tree water use option using FPC model; and (b) tree microclimate model with rainfall interception.

All programming, optimisation and modelling was conducted on the Queensland Department of Environment and Science's High Performance Computing (HPC) platform. For the baseline simulation called "before", the GRASP model was run with best estimates of vegetation and soil parameters for the Alice Mulga SuperSite without calibration. These best-estimate parameters were obtained from a property in the area with similar soils and vegetation (R. Cowley and C. Materne pers. comm.), with some of the parameters adjusted to better represent the site, based on known site values. Pasture biomass was estimated from photographs at the start of the simulation study. An optimisation experiment was conducted during the model improvement phase but only the final simulation is presented, called "after". This run included changes to GRASP model functionality.

Monthly runoff and evapotranspiration predictions were compared to the AWRA Model (Frost et al. 2018) and flux tower data. It is important to note that the AWRA model is run on a $5 \mathrm{~km}$ grid across Australia using a single set of parameters calibrated to streamflow, satellite evapotranspiration and soil moisture. It is also noted that flux tower evapotranspiration observations were not directly used for parameter calibration in the AWRA model, but flux tower evapotranspiration for four other sites was used to develop the structure of the vegetation, hydrology and phenology components of the AWRA model (van Dijk 2010). Drainage was compared to estimates in the Ti Tree basin by Harrington et al. (2002) and Chen et al. (2014). Tree transpiration rates were evaluated against data measured in the Ti Tree Basin for mulga by O'Grady et al. (2009).

\subsection{Parameter estimation and model optimisation}

Parameters were estimated using a Differential Evolution method (Storn and Price 1997), which is a simple and efficient method for global optimisation. The objective function was the root mean square error of the daily evapotranspiration predictions. Fifteen parameters were optimised to minimize the objective function, with parameters constrained within sensible limits based on prior knowledge. Parameters relating to tree root distribution, tree water use indices, relationship between FPC and potential transpiration, grass soil water indices, transpiration efficiency, potential soil evaporation and the pasture yield cover relationships were 
Owens et al., Improving evapotranspiration estimation in pasture and native vegetation models using flux tower data, remote sensing and global optimisation

optimised. Various statistics were calculated to assess the model's performance after calibration, including Pearson's correlation coefficient (r), Nash Sutcliffe Efficiency (NSE) and the coefficient of determination (Rsquared) around the 1:1 line. Model optimisation inevitably involves some form of compromise around choosing which parts of the evapotranspiration estimates to emphasise (daily peaks of high evapotranspiration or low rates during droughts or the dry season) as well as trade-offs when attempting to optimise to various groups of measured data (green cover, total cover and soil moisture). We explored various options through an optimisation experiment using all available data.

Observational data from flux tower and remote sensing were added to the GRASP database for automated calibration. A first optimisation round used daily soil moisture data from the flux towers, but this was later excluded due to trade-offs with evapotranspiration. Green cover calculations were adjusted in the model to prevent green grass obscured by dead material from absorbing solar radiation and being seen by satellite, and inverse modelling was used to better match satellite-derived data. Total daily evapotranspiration was limited to 1.3 times pan evaporation (Allen et al., 1998), although a lower limit of 1.0 times pan evaporation was explored.

A hard limit on tree transpiration was introduced as a model parameter following van Dijk (2010), representing a physiological maximum for root water uptake. An additional model option and parameter was added to limit daily tree transpiration using maximum tree transpiration per unit tree basal area following the approach by Calder et al. (1998) and Kelley et al. (2007, Figure 2), with FPC maintained to account for canopy removal events such as fire and drought. Kelley et al. (2007) concluded that within Australia, water use by trees during periods of high radiation load and high soil water content is a linear function of tree basal area, regardless of differences in species composition between ecosystems. The approach of Kelley et al. (2007) was useful as a guide to tree transpiration per unit tree basal area and will be used as a framework for compiling additional measurements for other sites in northern Australia. A review of the literature and site data demonstrated that lack of measurements of stand tree basal area and FPC make field measured tree transpiration data less useful for modelling or extrapolation to other sites. We estimated FPC and tree basal area using data from Sentinel. Knowledge of understorey biomass and cover is also

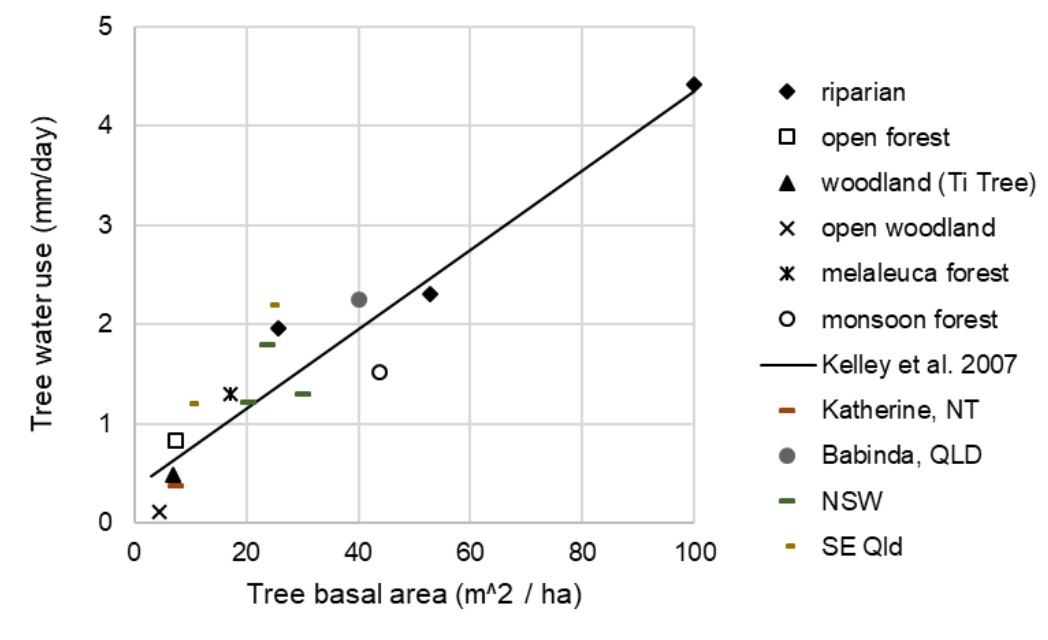

Figure 2. Tree basal area vs wet season tree water use for six diverse ecosystems of northern Australia. These data are average rates of water use observed in the wet season from Kelley et al (2007) with four additional measurements added. important when trying to partition evapotranspiration from flux tower observations into its components and including measurements of these are recommended to add value and help validate remote sensing and modelling.

\section{RESULTS AND DISCUSSION}

Improvement in daily and monthly evapotranspiration estimates by GRASP was obtained through model development and parameter optimisation with daily flux-tower evapotranspiration (Figures 3 and 4). Figure 3a

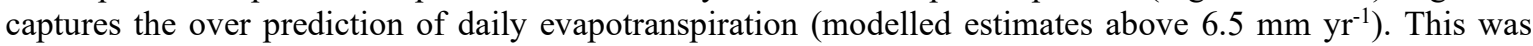
because soil water was evapotranspired too rapidly in the wet season, thereby prematurely drying the soil too rapidly compared to the flux tower data. Monthly evapotranspiration estimates by the GRASP model before improvements and calibration were reasonable but did not always capture the rapid changes in evapotranspiration and soil water content (Figure 4, $\mathrm{r}_{1: 1}^{2}$ of 0.88 , NSE 0.78, correlation 0.94). Aggregating from daily to monthly estimates improved the correlation against measured data (Figure $4, \mathrm{r}_{1: 1}^{2}$ of 0.97 , NSE 0.96, correlation 0.99). The AWRA model had a good correlation for total evapotranspiration with measured data $\left(\mathrm{r}^{2}{ }_{1: 1} 0.67\right.$, NSE 0.53 , correlation 0.85$)$. 
Owens et al., Improving evapotranspiration estimation in pasture and native vegetation models using flux tower data, remote sensing and global optimisation
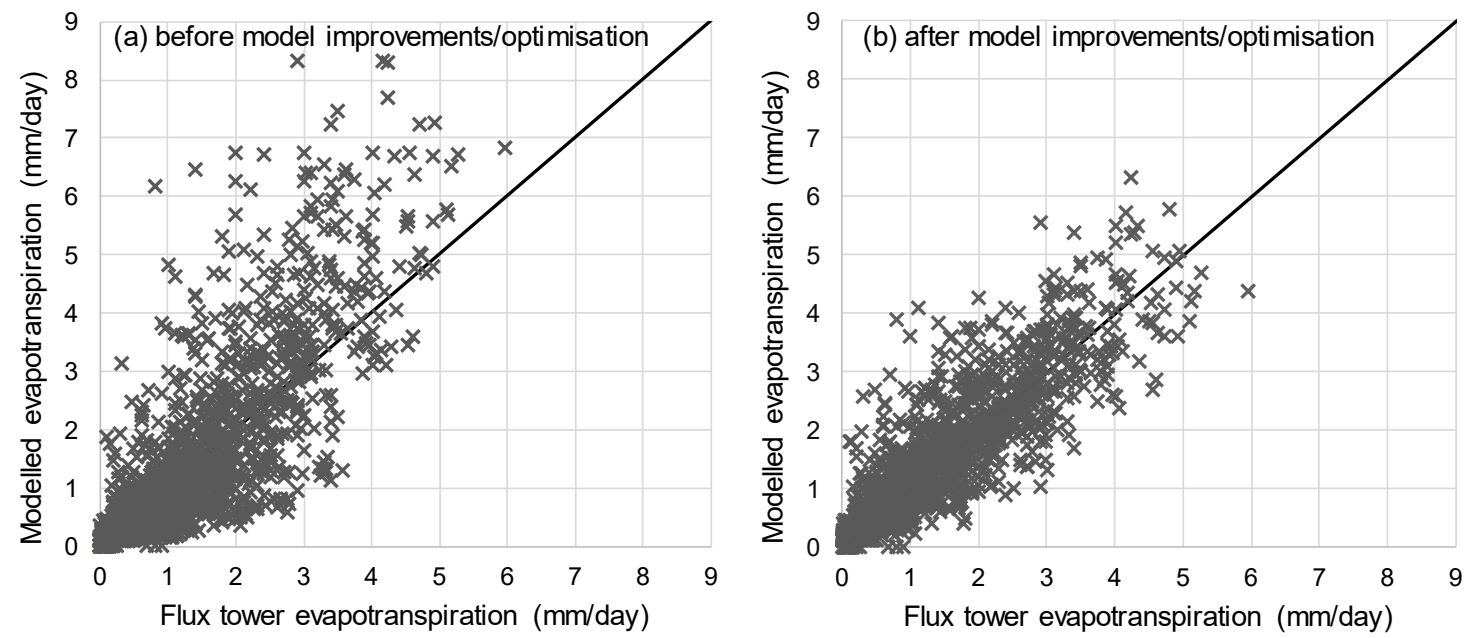

Figure 3. Daily evapotranspiration estimated by the GRASP model before $\left(\mathrm{r}^{2}{ }_{1: 1} 0.79\right.$, NSE 0.53 , correlation 0.86, slope 1.1, RMSE 0.67) and after model improvements and optimisation $\left(\mathrm{r}^{2}{ }_{1: 1} 0.86\right.$, NSE 0.81 , correlation 0.92, slope 1.0, RMSE 0.42) compared to flux tower data at the Alice Mulga site.

Runoff and recharge is low in this environment. Runoff estimates by the GRASP model were $c a .30 \mathrm{~mm} \mathrm{yr}^{-1}$ compared to the AWRA model which was lower at approximately $16 \mathrm{~mm} \mathrm{yr}^{-1}$. Previous studies in the $\mathrm{Ti}$ Tree basin suggest that little diffuse recharge occurs $\left(0.2\right.$ to $\left.2 \mathrm{~mm} \mathrm{yr}^{-1}\right)$ in the current climate regime except following very heavy rainfall events (Harrington et al. 2002). Low rates of drainage were modelled with GRASP (average $5 \mathrm{~mm} \mathrm{yr}^{-1}$ for the 8 year study period) with most of the recharge occurring in December 2016 when there was a period of high rainfall $(345 \mathrm{~mm}$ month $\left.^{-1}\right)$. This is consistent with the soilplant-atmosphere continuum modelling for this site by Chen et al. (2014), who found only one very small recharge event to occur between 1981 and 2012 (in 2001). Rainfall interception loss was approximately $12 \%$ of rainfall, which compares well to $13 \%$ measured in the mulga in southwestern Queensland by Pressland (1973).

The satellite green cover data highlighted that the effects of frost were not initially captured by the GRASP model at this site, as pasture characterisation measurements are usually carried out in summer and autumn (Figure 5). Frost parameters were adjusted to better represent the site for the final optimisation, and data are presented to highlight how satellite data can be used in grazing trials in the absence of measured field data. Total understorey cover was in close agreement between satellite and GRASP over the 8 years, indicating that the simulation of total standing dry matter for grasses was being predicted reasonably well (Figure 5). In the case of green cover, the simulated peaks were in close alignment with Landsat data. However, the decline in simulated green cover was often more rapid than for Landsat. The results suggest that the parameterisation of senescence (transfer of green to dead tissue) could be improved, concentrating on the effects of soil water stress and frost. The model was calibrated to evapotranspiration data and not satellite-derived cover data and is a good independent evaluation of pasture biomass and cover estimated by GRASP (Figure 5). We are mindful of the uncertainty associated with satellite-derived cover data and used it for evaluation purposes only. 
Owens et al., Improving evapotranspiration estimation in pasture and native vegetation models using flux tower data, remote sensing and global optimisation

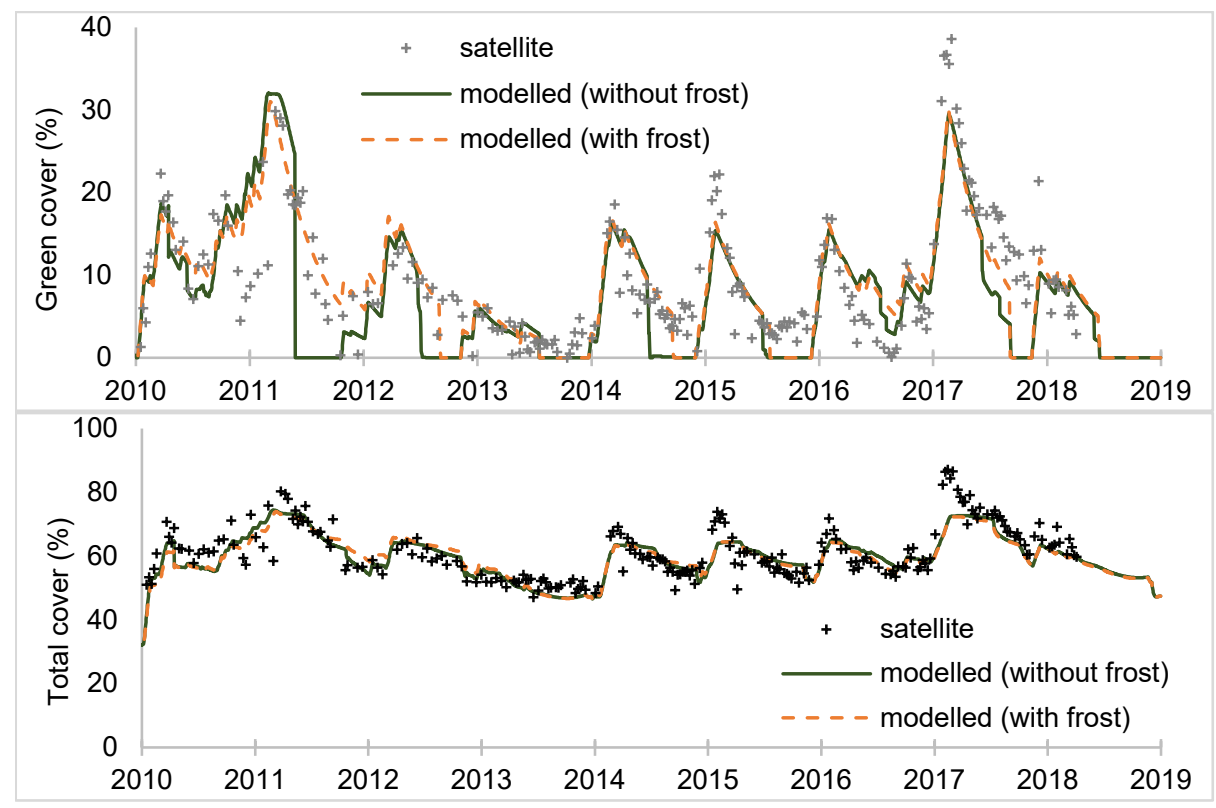

Figure 5. Green and total understorey cover estimated by the GRASP model after model improvements and optimisation compared to Landsat fractional cover at the Alice Mulga site. The dotted line shows improvements in green cover estimates after better frost parameters were used.

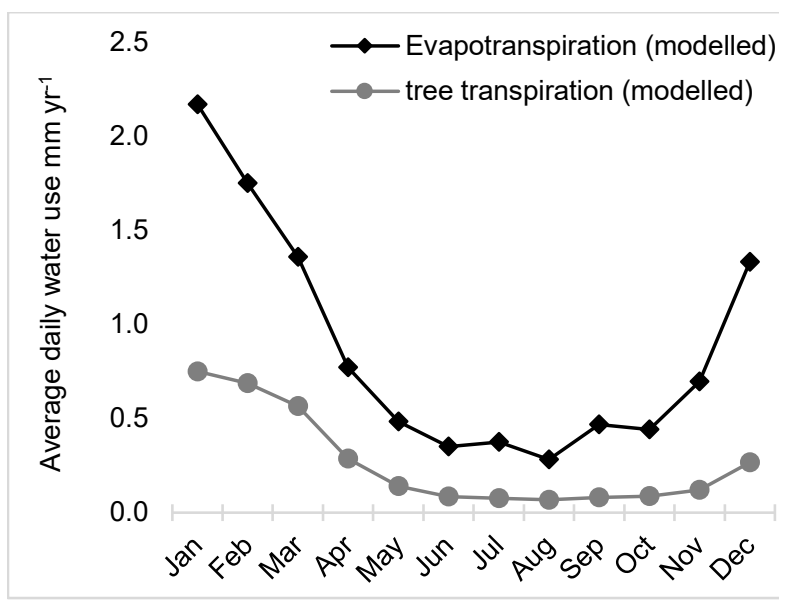

Figure 6. Average daily tree transpiration and evapotranspiration for each month estimated by the GRASP after model improvements and optimisation.
Tree transpiration estimates were evaluated with measured data using sapflow loggers for mulga in the Ti Tree basin by O'Grady et al. (2009). They measured tree transpiration in the late wet season (April) to represent a period of high water availability following high summer rainfall $\left(0.49 \mathrm{~mm} \mathrm{day}^{-1}\right)$, and in the late dry season in November following a period of very little winter rainfall $\left(0.18 \mathrm{~mm} \mathrm{day}^{-1}\right)$, for a tree basal area of about $7 \mathrm{~m}^{2} \mathrm{ha}^{-1}$. Tree basal area at the flux tower was approximately 30\% higher than at the sapflow site. Average estimated tree transpiration with GRASP was comparable to sapflow measurements (averaging $0.44 \mathrm{~mm}^{\text {day- }}$ ${ }^{1}$ in the wet season and $0.09 \mathrm{~mm} \mathrm{day}^{-1}$ in the dry season for the period of study from 2008 to 2018; Figure 6). Modelled average daily tree transpiration rates in April ranged $0.01 \mathrm{~mm}^{-}$ 1 to $0.82 \mathrm{~mm} \mathrm{day}^{-1}$. Modelled averages in November ranged from $0 \mathrm{~mm}_{\text {day }}{ }^{-1}$ to $0.38 \mathrm{~mm}$ day $^{-1}$.

Optimisation experiments identified where the model needed improving as implausible parameters and or poor reduction in error provided characteristic diagnostics of problems. There are trade-offs to consider when optimising using multiple parameters against multiple observation types (e.g. evapotranspiration, soil moisture, cover and biomass) as most parameters impact the model ability to reproduce all observation types. Improvement in model functionality generally requires re-optimisation of model parameters as model changes often de-calibrate the prior parameter settings. Further improvements in estimating daily flux measurements probably requires hourly modelling and hourly inputs of evapotranspiration and rainfall and a better understanding of grass and tree fine root development after prolonged dry periods. Model parameterisation allows us to explore the interplay between different parameters and key model processes and gain a better understanding of the model. The parameterisation and evaluation attempted to take into account some of the uncertainty associated with the rainfall and climate data, flux tower evapotranspiration data and satellitederived green cover and FPC data. 
Owens et al., Improving evapotranspiration estimation in pasture and native vegetation models using flux tower data, remote sensing and global optimisation

\section{CONCLUSION}

A quote from T.S. Elliot sums up our experience with these optimisation experiments: "We shall not cease from exploration, and the end of all our exploring will be to arrive where we started and know the place for the first time". This is exactly the same situation we discovered where a detailed exploration of the optimisation experiments gave us new insights into the GRASP model functionality and revealed that optimisation alone was not going to solve the problem until model changes happen first.

This study provides parameterisation for improving the modelling of mulga woodland savannas with Cedar GRASP, FORAGE and AussieGRASS models, as well as improvements for all woody vegetation. We demonstrate how satellite-derived vegetation cover data and flux tower measurements can be used to enhance the modelling of grass and woodland systems; the framework for these new observations are now available with the GRASP model as well as automated calibration tools. Modelled and measured daily evapotranspiration agreed after model improvement and optimisation, with the agreement improving as data were aggregated to monthly values. We have significantly more confidence in modelling the rate of tree transpiration and total evapotranspiration as a result of this work. These findings have important implications for modelling the competition of water between grasses and trees in woodland systems especially under changing rainfall and increasing rain intensity expected with climate change and the impacts this may have on the grazing industry.

\section{ACKNOWLEDGEMENTS}

This work would not have been possible without the TERN flux tower data and we gratefully acknowledge the OzFlux network. We acknowledge the Australian Bureau of Meteorology and SILO for providing daily climate data. We are very grateful to Dr Robyn Cowley and Chris Materne of NT DPI for pasture characterisation data from Alice Springs; Dr Anthony O'Grady for tree transpiration data; Mathew Pringle for python scripts to estimate fractional cover from Landsat and Neil Flood for extracting FPC data from Sentinel to allow comparisons of tree density. We acknowledge Dr Greg McKeon, developer of the GRASP model for reviewing this manuscript and for his relentless support for this work. We acknowledge funding from the Queensland Drought and Climate Adaptation Program (DCAP) and the Queensland Reef Water Quality Program.

\section{REFERENCES}

Allen, R.G., Pereira, L.S., Raes, D. and Smith, M., (1998). Crop Evapotranspiration. Irrigation and Drainage Paper 56. United Nations FAO, Rome, Italy.

Calder, I. (1998). Water use by forests, limits and controls. Tree Physiology. 18. 625-631.

Chen, C., Eamus, D., Cleverly, J., Boulain, N., Cook, P., Zhang, L., Cheng, L., and Yu Q. (2014). Modelling vegetation water-use and groundwater recharge as affected by climate variability in an arid-zone Acacia savanna woodland, Journal of Hydrology, 519, 1084-1096.

Cleverly, J., Boulain, N., Villalobos-Vega, R., Grant, N., Faux, R., Wood, C., Cook, PG., Yu, Q., Leigh, A., and Eamus, D. (2013). Dynamics of component carbon fluxes in a semi-arid Acacia woodland, central Australia, Journal of Geophysical Research - Biogeosciences, 118, 1168-1185.

Day, K.A., McKeon, G.M. and Carter, J.O. (1997). Evaluating the risk of pasture and land degradation in native pastures in Queensland, Final Report on DAQ124A to RIRDC (six volumes).

Eamus, D., Huete, A., Cleverly, J., Nolan, R., Ma, X., Tarin, T. and Santini, N. (2016). Mulga, a major tropical dry open forest of Australia: Recent insights to carbon and water fluxes. Environmental Res. Letters, 11, 18.

Frost, A. J., Ramchurn, A. and Smith, A. (2018). The Australian Landscape Water Balance model AWRA-L v6. Technical Description of the Australian Water Resources Assessment Landscape model version 6. Bureau of Meteorology Technical Report.

Harrington, G., Cook, P.G. and Herczeg, A.L. (2002). Spatial and temporal variability of ground water recharge in central Australia: a tracer approach. Groundwater 40, 518-528.

O'Grady A.P., Cook P.G., Eamus D., Duguid A., Wischusen J.D.H., Fass T. and Worldege D. (2009). Convergence of tree water use within an arid-zone woodland, Oecologia, vol. 160, 643-655.

Rickert, K.G., Stuth, J.W. and McKeon, G.M. (2000). Modelling pasture and animal production. In: 'Field and Laboratory Methods for Grassland and animal Production Research'. (Eds L.'t Mannetje and R. M. Jones.) pp. 29-66. CABI Publishing: New York.

Storn, R. and Price, K. (1997). Differential evolution - a simple and efficient heuristic for global optimization over continuous spaces. Journal of Global Optimization, 11, 341-359. 